\title{
Application of modified Maple Wood Saw Dust with Polyaniline for the Removal of Anionic Dyes From Waste water : Kinetics and IsothermStudies
}

\author{
A.A. Emam*,Nora M Hilal, A. A. El-Bayaa, N.A. Badawy, andU.A. Ghiat \\ Chemistry Department, Faculty of Science, Al-Azhar University (Girls), Nasr City, Cairo, Egypt \\ *a_a_emam@yahoo.com
}

\begin{abstract}
:
In this work, application of polyaniline coated onto wood sawdust (PAni/SD) for the removalof anionic dyes namely Reactive Red 43 (RR43 dye) and Direct Orang 85 (DO85 dye) from aqueous solutions is introduced.Maple wood sawdust was characterized by FourierTransform-Infrared Spectroscopy (FTIR),Scanning ElectronMicroscopy (SEM).The effects ofsome important parameters such as $\mathrm{pH}$, initial concentration, sorbent dosage, and contact time onthe uptake of anionic dyes solution were also investigated. In order to get a better comparison, adsorptionexperiments were also carried out using polyaniline coated maple wood saw dust (PAni/MWSD) and without coating (MWSD). It was found that PAni/MWSD can be used to removeanionic dyes such as DO85 and RR43 dyes from aqueous solutions very efficiently. Experimental data were analyzed bythe Langmuir,Freundlichand Temkinmodels of adsorption. Kinetic parameters for the adsorption of anionicdyes for the selected adsorbents are also reported. Application of modified sawdust with polyaniline for the removal of anionic dyesisvery promising for wastewater treatment.
\end{abstract}

Keywords: MWSD, polyaniline coated MWSD .anionic dyes,adsorption, kinetics and isotherm studies.

\section{Introduction}

Totally, 280,000 tons of 10,000 different classes of annuallyconsumed dyes in textile industry and dye houses are introducedinto the environment by either direct discharging or during subsequenttextile processes (G_oeset al., 2016; Maas and Chaudhari,2005). This is while, only small concentration of dyes, i.e. about1 ppm, is high enough to affect water quality (Crini, 2006; Rafatullahet $a l ., 2010)$. Common wastewater purification systemshave low efficiency in some classes of anionic dyes such as reactiveand acidic dyes, while they are also resistant against aerobicdegradation (Robinson et al., 2001). In addition, other processessuch as ozonation, reverse osmosis, coagulation and flocculationsuffer from problems including cost limitations and sludge production.Further, some of the mentioned processes are not practicalin low dye concentration levels (Lee et al., 2016).

Nowadays, economic and environmental friendly approaches such as adsorbing to refine wastewater have found great attention. In this regard, nylon-polyanilinenanocomposite web with high dye desorption capacity is developed. This is implemented through in-situ polymerization of polyaniline on the surface of electrospun nylon-6 nanofibers( Kamran Zarrini, et al., 2017). Polyaniline is one of the most studied conductive polymers with high environmental and thermal stability which have found many applications. This polymer can be easily synthesized through achemically/electrochemically oxidative polymerization process(Chen et al., 2011a; Jaymand, 2013; Syed and Dinesan, 1991).

The by-products from the forestry and agricultural industries could be assumed to be low-cost adsorbents since they are abundant in nature, inexpensive, require little processing and are effective materials. Saw dust is an abundant by-product of the wood industry that is either used as cooking fuel or as packing material (Garget al.,2004). Saw dust is easily available at negligible price. The role of saw dust materials in the removal of pollutants from aqueous solutions has been reviewed recently (Shukla et al.,2002). Sawdust has proven to be a promising effective material for the removal of various dyes. (VenkatandVijay Babu,2013).

Hence in the present study, the maple wood saw dust considered to be awaste has been used effectively as an adsorbent. Thus the prepared polyanilinecoatedsawdust was used as an adsorbent for the removal of two different types of dyes namely Reactive Red43 and Direct Orange 85 from aqueous solutions. The study includes an evaluation of the effects ofvarious parameters like initial dye concentration, contact time and $\mathrm{pH}$. The adsorption kineticmodels, equilibrium isotherm models related to adsorption process were a slope formed and reported. 


\section{Experimental}

\subsection{Adsorbents(Maple wood sawdust)}

Maple wood sawdust samples were collected from a local Damietta Port - Egypt. The maple wood sawdust samples were sieved through $0.355 \mathrm{~mm}$ and it was used directly for adsorption experiments without any physical and chemical treatments.

The sawdust supplied by a local wood processing factory was washed with distilled water to remove impurity, and then dried overnight at $60^{\circ} \mathrm{C}$. The dried sawdust was sieved to retain the $0.355 \mathrm{~mm}$ fractions for further chemical synthesis. $140 \mathrm{~mL}$ of $\mathrm{HCl}$ concentrated (Merck, Germany) was added to 10 g of sawdust.

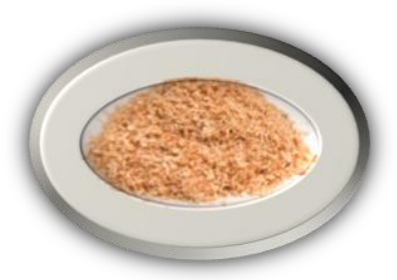

\subsection{Preparation of PANi/SD and adsorption experiments}

Sawdust $(5.0 \mathrm{~g}, 0.355 \mathrm{~mm}, 10 \%$ humidity) was immersed in an aqueous aniline solution $(0.2 \mathrm{M}$, $100 \mathrm{~mL}$ ) for $12 \mathrm{~h}$ before polymerization. The excess of the monomer solution was removed by simple decantation. The amount of $50 \mathrm{~mL}$ of the oxidant solution, an aqueous solution $(0.2 \mathrm{M})$ of $\left(\mathrm{NH}_{4}\right)_{2} \mathrm{~S}_{2} \mathrm{O}_{8}$, was added into the mixture dropwise and the reaction was allowed to continue for $5 \mathrm{~h}$ at room temperature. Resulting PAni/SD was filtered, washed with distilled water, and dried in an oven at $60{ }^{\circ} \mathrm{C}$. In order to increase the reproducibility of the results, PAni/SD was sieved before use. Particles of $0.355 \mathrm{~mm}$ size were selected for adsorption experiments. Batch mode studies were conducted with fixed amounts $(0.1 \mathrm{~g}$ to $1.0 \mathrm{~g})$ of adsorbents which were shaken separately in an aqueous solution of the dye (40 $\mathrm{mL}$ ) of varying concentration $(5-100 \mathrm{ppm})$ at room temperature for definite time periods. At the end of the pre-determined time intervals, the adsorbent was removed by simple filtration.

\subsection{Determination of $\mathrm{pH}$ point of zero charge}

Point of zero charge is of fundamental importance in environmentalscience. It determines howeasily a substrate is able to adsorb potentiallyharmful ions. The $\mathrm{pH}$ point of zero charge $\left(\mathrm{pH}_{\mathrm{pzc}}\right)$ was carried out bytaking $50 \mathrm{ml}$ of $0.01 \mathrm{M} \mathrm{NaCl}$ solution in different closed Erlenmeyerflasks. The $\mathrm{pH}$ of the solution $\left(\mathrm{pH}_{\mathrm{o}}\right)$ in each flask was adjusted to valuesof $2,4,6$, 8and 10 by adding $0.1 \mathrm{MHCl}$ or 0.1 MNaOHsolutions. Then $0.5 \mathrm{~g}$ of the adsorbent was added and agitated in a shaker for $1 \mathrm{~h}$ andallowed to stay for $48 \mathrm{~h}$ to reach equilibrium with intermittent manualshaking. Then the final $\mathrm{pH}$ value $\left(\mathrm{pH}_{\mathrm{f}}\right)$ of the supernatant liquid wasnoted. The difference between the initial and final $\mathrm{pH}$ values $\left(\Delta \mathrm{pH}=\mathrm{pH}_{\mathrm{o}}-\mathrm{pH}_{\mathrm{f}}\right)$ was plotted against the $\mathrm{pH}_{\mathrm{o}}$. The point of intersectionof the resulting curve at which $\Delta \mathrm{pH}=0$ gave the $\mathrm{pH}_{\mathrm{pzc}}$ (M.S. Onyangoet al., 2004;V.C. Srivastavaet al., 2008)

\subsection{Adsorbate}

The dyes used were Reactive Red43 (RR43) and Direct Orange85 (DO85) which are anionic in nature.The stock solution was prepared by dissolving $1 \mathrm{~g}$ of dye in water and upto $1000 \mathrm{ml}$ using double distilled water.The concentration of the dye solution was determined by using UV-Spectrophotometer (Elico make BL198) at its wavelength (503 nmfor Reactive red43 and483 nm for Direct Orange85).

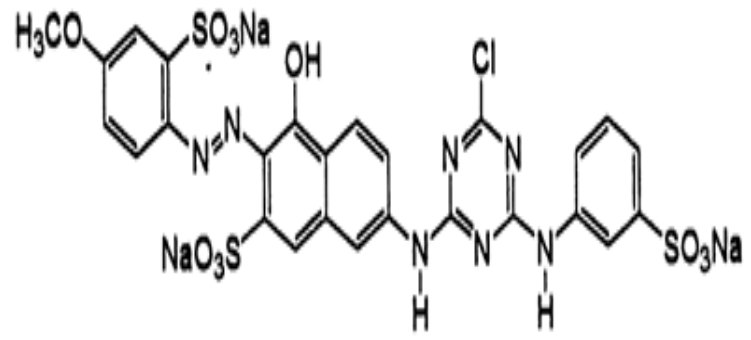

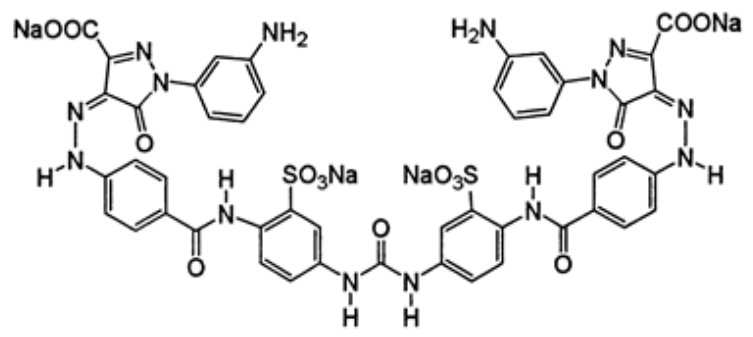

\section{Reactive red 43Direct Orange 85}


Dyes concentrations in the filtrate solutions were estimatedby measuring the absorbance at maximumwavelengthof the dye and computed from the calibrationcurves. The following equations were used tocalculate the percentage of adsorption and the amountof adsorbed (RR43,DO85) respectively:

$$
\begin{aligned}
& \text { Adsorption }=\frac{\left(C_{o}-C_{e}\right)}{C_{o}} \times 100 \\
& \frac{X}{m}=\frac{\left(C_{o}-C_{e}\right) V}{m} \text { or } \frac{X}{m}=\frac{R \times C_{o} \times V}{100 m}
\end{aligned}
$$

where $\mathrm{C}_{0}$ and $\mathrm{C}_{\mathrm{e}}$ are the initial and equilibrium concentrations $\left(\mathrm{mg} \mathrm{L}^{-1}\right.$ ) of (DO85,RR43), respectively, $\mathrm{X} / \mathrm{m}$ is theamount of dye adsorbed onto a unit amount of theadsorbent $\left(\mathrm{mg} \mathrm{g}^{-1}\right)$ at equilibrium, $\mathrm{V}$ is the volume $(\mathrm{L})$ of the solution used in the adsorption experiment,and $\mathrm{R}$ is the percentage of dye removal.

\section{Results and discussion}

\subsection{Characterization of the adsorbent}

FT-IR spectrum of the sawdust (SD) (Figure 1) showed the most prominent peaks in the spectrum originate from hydroxyl group, which was probably attributed to adsorbed water $\left(3854 \mathrm{~cm}^{-1}\right)$ and $\mathrm{CH}_{2}$ and $\mathrm{CH}_{3}$ asymmetric and symmetric stretching vibrations $\left(2871 \mathrm{~cm}^{-1}\right)$. The spectrum of the MWSD also displayed number of peaks corresponding to the presence of many functional groups: $\mathrm{NH}$ stretch $\left(2322 \mathrm{~cm}^{-1}\right), \mathrm{C}=\mathrm{O}$ stretching $\left(1733 \mathrm{~cm}^{-1}\right), \mathrm{CO}$ chelate stretching $\left(1653 \mathrm{~cm}^{-1}\right)$, secondary amine $\left(1507 \mathrm{~cm}^{-1}\right)$, symmetric bending of $\mathrm{CH}_{3}\left(1457 \mathrm{~cm}^{-1}\right), \mathrm{CH}_{2}$ bending $\left(1428 \mathrm{~cm}^{-1}\right), \mathrm{C}-\mathrm{N}$ vibration in primary amide $\left(1368 \mathrm{~cm}^{-1}\right), \mathrm{C}-\mathrm{O}$ stretching $\left(1272 \mathrm{~cm}^{-1}\right), \mathrm{O}-\mathrm{H}$ bending $\left(1245 \mathrm{~cm}^{-1}\right), \mathrm{C}-\mathrm{O}$ antisymmetric stretching $\left(1162 \mathrm{~cm}^{-1}\right)$, stretching of the many C-OH and C-O-C bonds $\left(1054 \mathrm{~cm}^{-1}\right)$ [Stuart], C-H $\left(835\right.$ and $897 \mathrm{~cm}^{-}$ $\left.{ }^{1}\right)$, Al-OH deformation $\left(787 \mathrm{~cm}^{-1}\right)$, Al-O deformation $\left(671 \mathrm{~cm}^{-1}\right)$ and $\mathrm{SiO}\left(541 \mathrm{~cm}^{-1}\right)$. On comparing spectrum of MWSD with modified MWSD, it could be seen that there were strong characteristic stretching vibration absorption band of carboxyl group $\left(1732 \mathrm{~cm}^{-1}\right)$ and $\mathrm{C}-\mathrm{N}$ vibration of primary amide $\left(1384 \mathrm{~cm}^{-1}\right)$. It reflected the result of modified sawdust (Figure 1). The spectrum of reactive red 43 (RR 43), direct orange 85 (DO85) loaded MWSD and treated MWSD also exhibited small shift in some bands and some bands were disappeared. The intensity of the peaks were either minimized or shifted slightly as shown in Figure (1). These changes observed in the spectrum indicated the possible involvement of these functional groups on the surface of the MWSD and treatedMWSD in adsorption process.

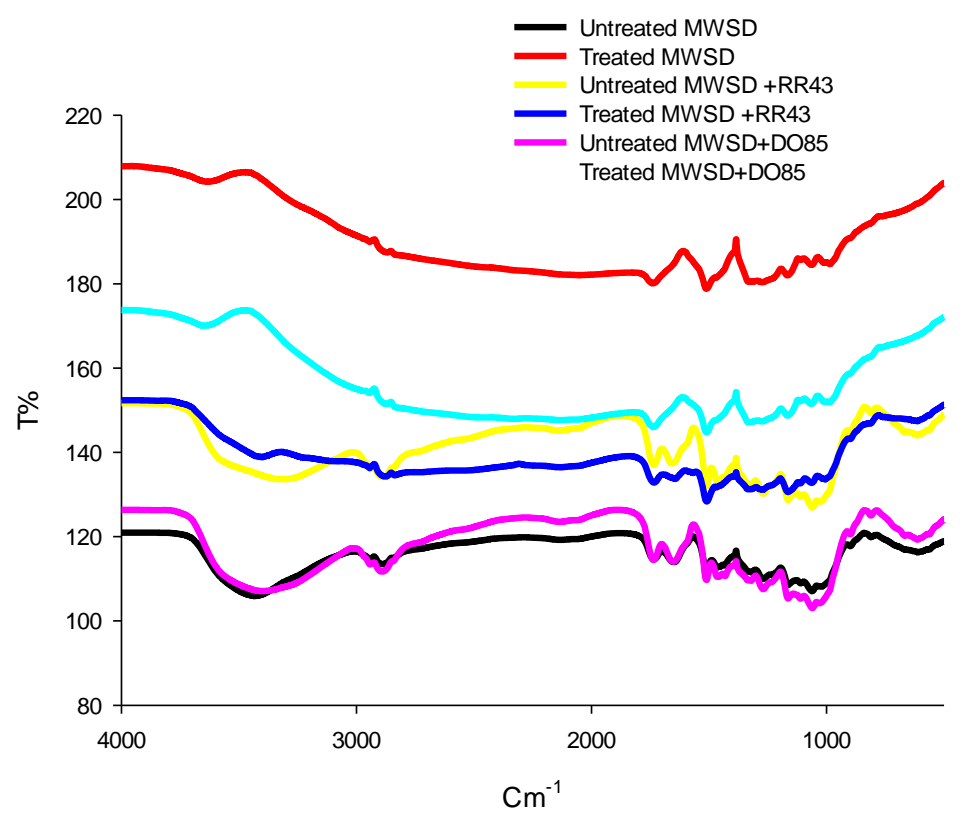

Fig. (1):FT-IR spectrum of both (MWSD) and (TMWSD), ( MWSD adsorption by RR43 and DO85) and (TMWSD adsorption by RR43 and DO85 system).

Scanning electron microscopy (SEM) is known as an efficient technique for investigation and evaluation of the surface morphology of adsorbed. SEM of both untreated (MWSD) and treated 
MWSDare shown in Fig. ( 2,3). Scanning electron microscope was used to investigate the surface morphology ofMWSD and TMWSD as shown in Figure ( 2 ). The SEM image before dye adsorption revealed the rough surface of MWSD and TMWSD. The rough surface micrograph shows ridge like structure within which the presence of the macro poreswere clearly noticeable. These rough surfaces and the macro pores were responsible for the high surface area, making MWSD and TMWSD a good adsorbent. The SEM image of TMWSD after adsorption RR 43 or DO85 showed smooth surface because the dye molecules were trapped and adsorbed on its surfaceFig. $(3,4)$.
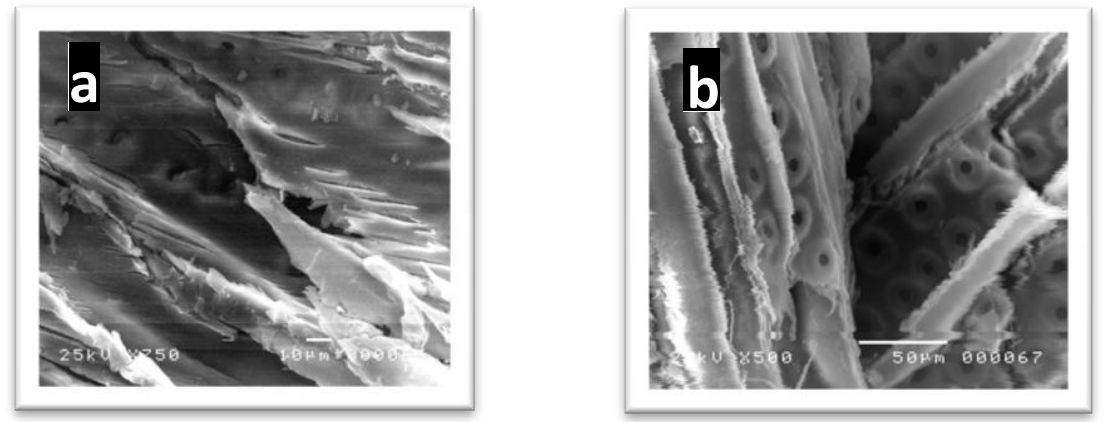

Fig.(2). SEM of both a-untreated (MWSD) and b- treated maple wood sawdust (TMWSD) .
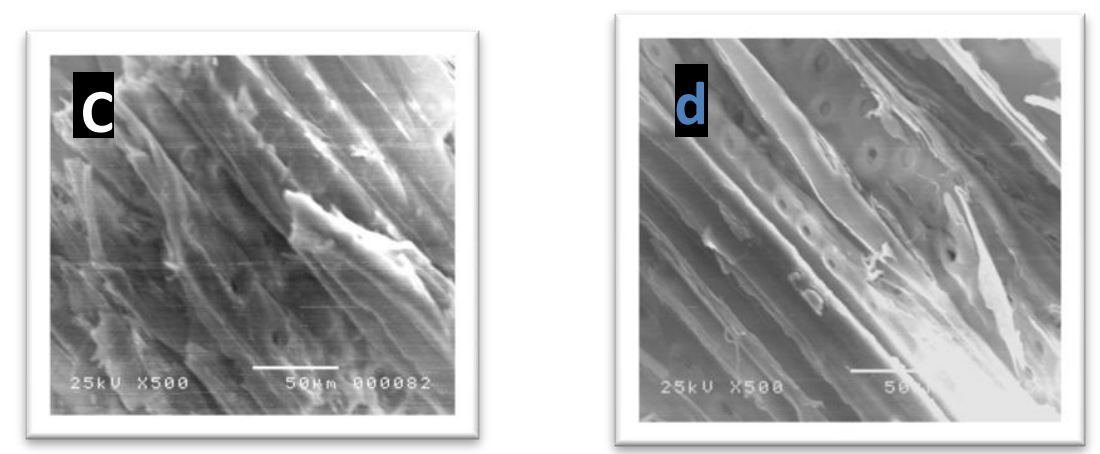

Fig.(3). SEM of untreated maple wood sawdust (MWSD) adsorption by c- DO85 and d-RR43 system.
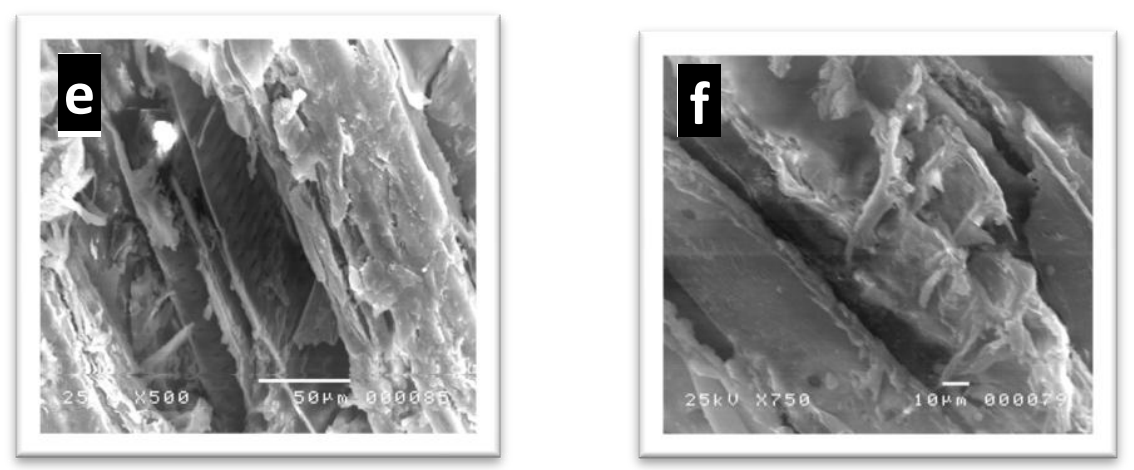

Fig.(4). SEM of treated maple wood sawdust (MWSD) adsorption by e- DO85 and f-RR43 system.

\subsection{The effect of $\mathrm{pH}$ on the adsorption process}

Fig. (5a) shows the plot of point of zero charge $\left(\mathrm{pH}_{\mathrm{pzc}}\right)$ for the tow adsorbents (MWSD and TMWSD). The $\mathrm{pH}_{\mathrm{pzc}}$ is a point at which the surface acidic (or basic) functional groups no longer contribute to the $\mathrm{pH}$ value of the solution. The $\mathrm{pH}_{\mathrm{pzc}}$ of MWSD and TMWSD were foundto be 6.32 and 4.32 respectively. It can be concluded that saw dust modified with polyanilline acidic surface since pH value of point of zero charge for TMWSD is at a lower $\mathrm{pH}$ compared to the valuereported for MWSD. The surface acidity was due to the introduction ofseveral oxygen-containing functional groups (P.C.C. Fariaetal.,2004). 
To investigate the effect of $\mathrm{pH}$ on the RR43 and DO85 adsorption, RR43 and DO85 solution (40 $\mathrm{mL}, \mathrm{c}=15 \mathrm{ppm}$ ) was treated with $0.7 \mathrm{gm}$ portions of dried sorbent (MWSD, PAni/MWSD) at various $\mathrm{pH}$ (1-10)(Fig.5b) As can be seen, the highest sorption percentage of RR43 and DO85 was observed for PAni/MWSD at $\mathrm{pH}$ values from 4 to 8 . It is interesting to note that removal efficiency of MWSD is a popular and well established adsorbent in dye removal. However, its application in textile waste water treatment has been limited due to its high cost and poor regenerate ability. Removal of RR43 and DO85 using the introduced adsorbent is also higher compared to both MWSD at pH values from 4-8. Removal of dyes by PAni/MWSD might be mostly due to the strong intermolecular interactions (e.g. H-bonding) of RR43 and DO85 with the polymer. The same reason can be proposed for RR43 and DO85 removal by MWSD which has different functional polar groups in its constituent (e.g. lignin, cellulose, hemicellulose) (Lebo et al, 2001). Adsorption ability of MWSD is mainly due to its porosity and great surface area which helps to entrap adsorbates such as dye molecules.

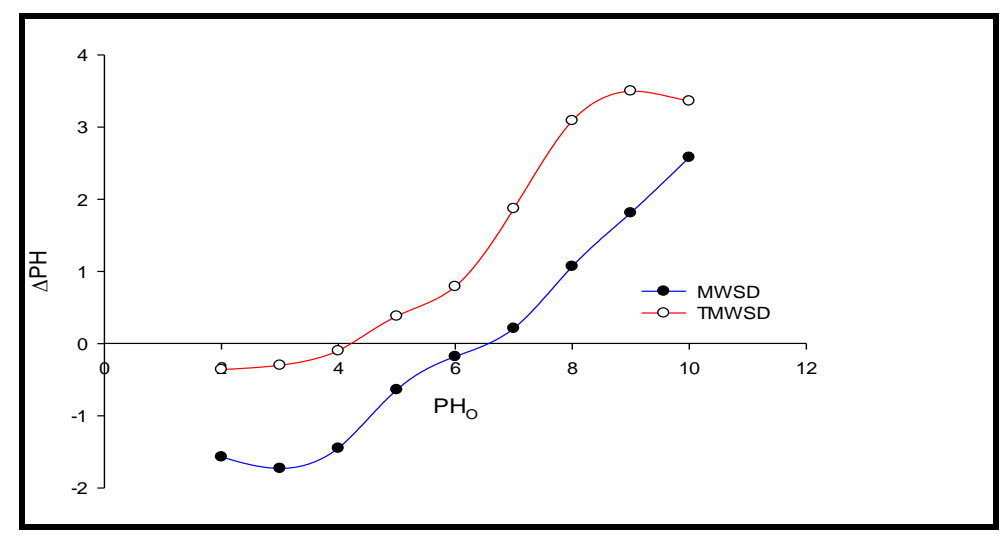

Fig. (5a)The zero point charge of MWSD and TMWSD.
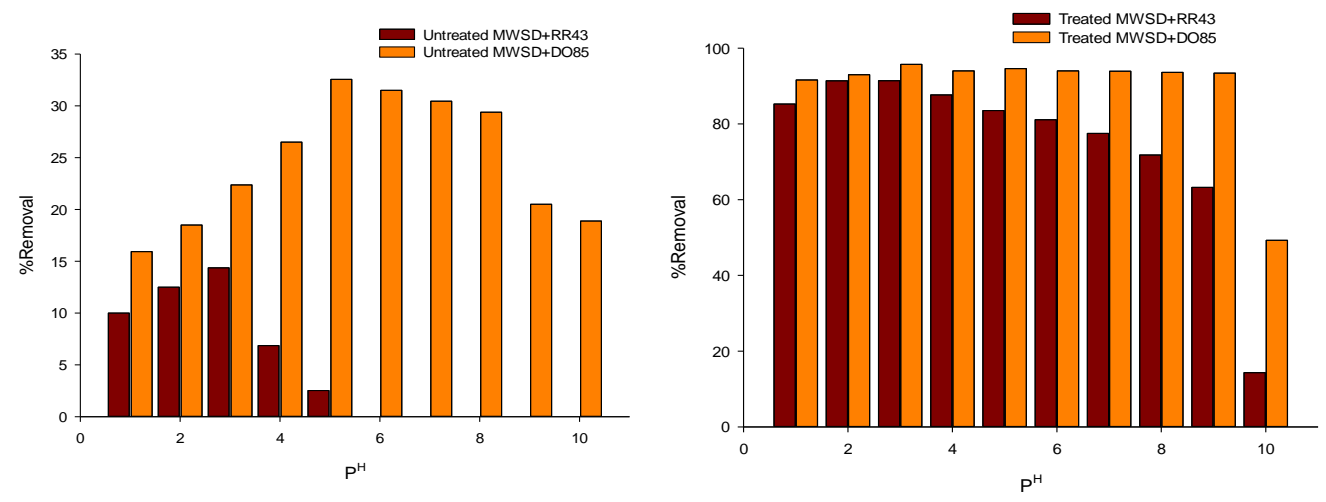

Fig.(5b)Effect of pH on the removal of RR43 and DO85: MWSD, PAni/MWSD.

\subsection{Effect of adsorbent dosage}

In these experiments, RR43 and DO85 solution $(40 \mathrm{~mL}, \mathrm{c}=15 \mathrm{ppm})$ was treated with

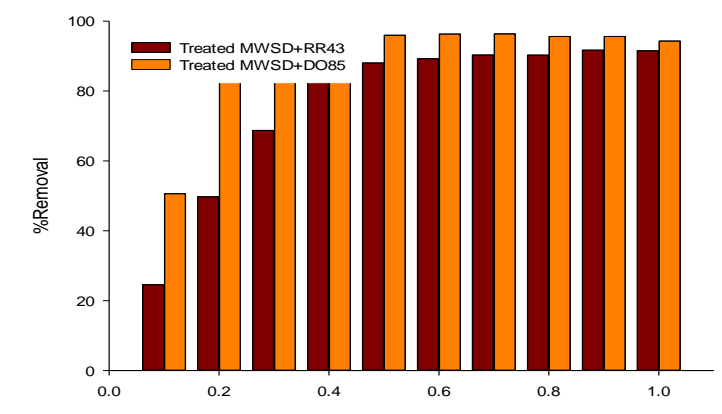


different amounts of the selected adsorbent (MWSD, PAni/MWSD) (0.1-1.0 g). As seen from the results depicted in Fig. 6, higher sorption percentage of RR43 and DO85 was observed for PAni/MWSD for all examined sorbent dosages. Increase of removal percentage with the increasing adsorbent dose can be due to the higher adsorption sites available for interaction with the RR43 and DO85 molecules. It is evident that RR43 and DO85 removal percentage observed for PAni/MWSD is even higher than for MWSD which is a well established and commonly used adsorbent for decolorization. However, its high cost has limited its use considerably.

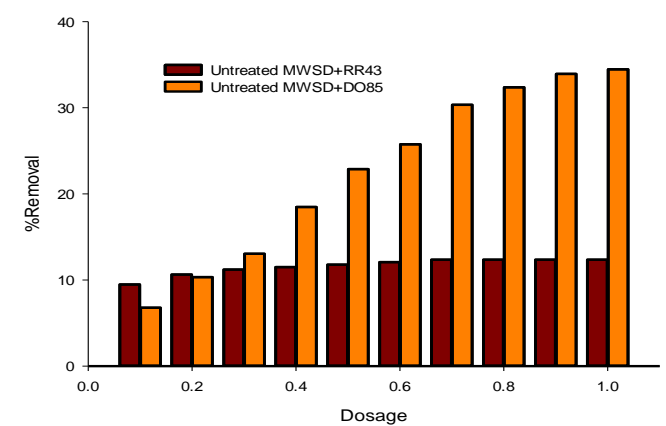

Fig. 6.Effect of adsorbent dosage on the removal of RR43 and DO85: MWSD, PAni/MWSD.

\subsection{Effect of initial concentration}

As our results show, at any $\mathrm{C}_{0}$ of DO85 and RR43, higher sorption percentage was observed for PAni/MWSD compared to uncoated MWSD and a comparable or higher value of DO85 than that for RR43. High removal percentage of DO85 and RR43 using polyaniline might be due to high affinity and strong intermolecular interactions between (RR43,DO85)diazo groups ( $-\mathrm{N}-\mathrm{N}-$ ), and polyaniline polymers which contain alternative imine and amino groups in their structures (Figs. 7) .(Reza Ansari* and Zahra Mosayebzadeh,2011).
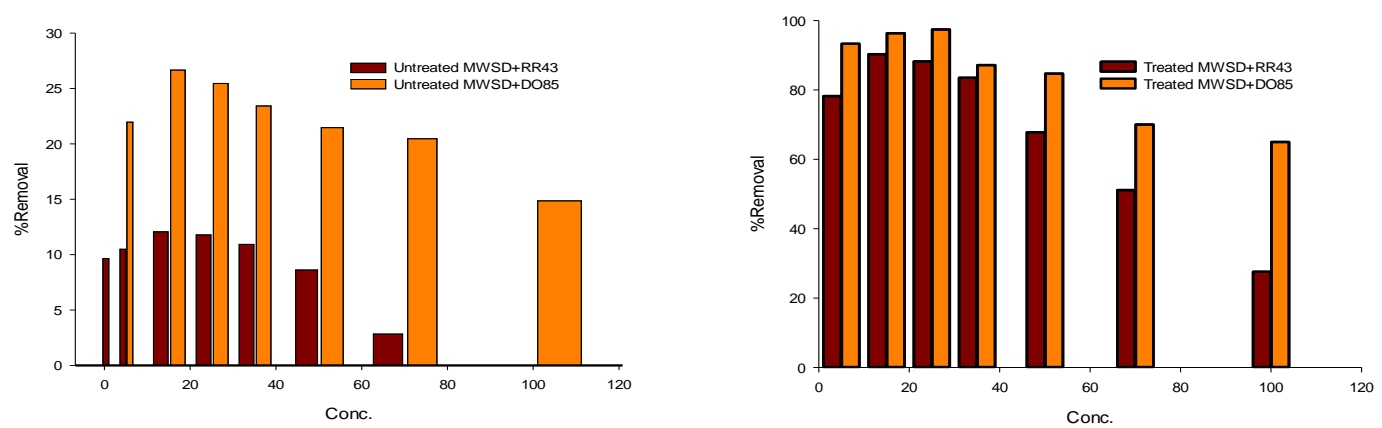

Fig.7. Effect of initial concentration of RR43 and DO85 (ppm) on the adsorptionby MWSD, PAni/MWSD.).

\subsection{Effect of contact time}

DO85 and RR43 solution ( $40 \mathrm{~mL}, \mathrm{C}=15 \mathrm{ppm}$ ) was treated with $0.7 \mathrm{~g}$ of selected adsorbent (MWSD, PAni/MWSD) for different periods of time (5-120 min) with stirring at room temperature. Results of the adsorption obtained from the analysis of unabsorbed RR43 and DO85 solution are shown in Fig. 8. The results indicate higher removal efficiency observed for PAni/MWSD at all exposure times compared to SD adsorbents. Removal of RR43 andDO85using PAni/MWSD is also very favorable from the kinetic point of view. Removal of RR43 andDO85 higher than $90 \%$ occurred at the initial stage of exposure .
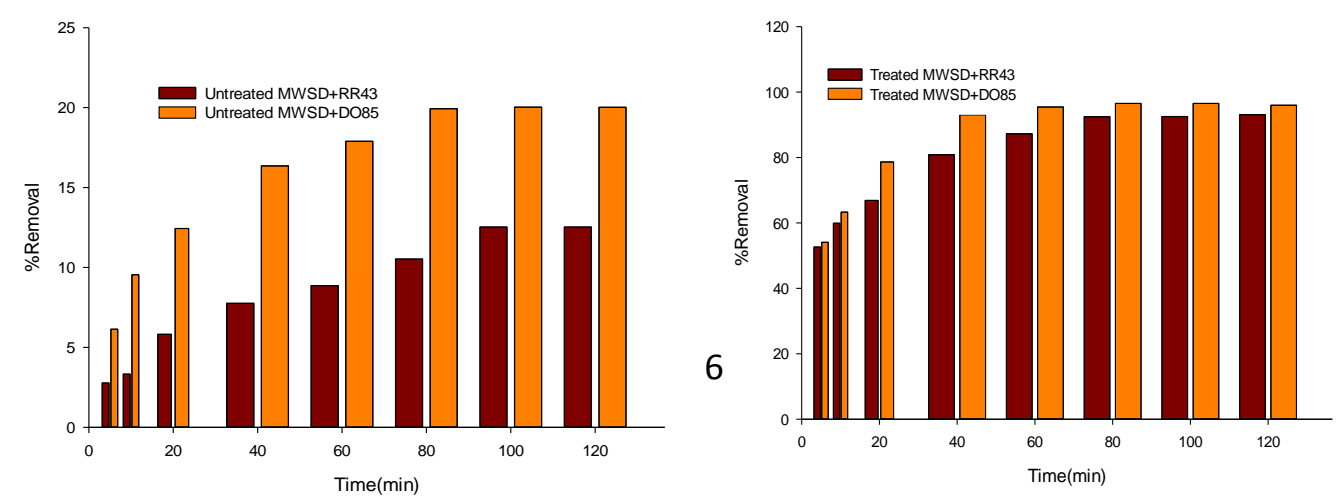
Fig. 8.Effect of contact time on the removal percentage of RR43 and DO85 (ppm) on the adsorptionby MWSD, PAni/MWSD.)

\subsection{Kinetics modeling}

Study of removal kinetics is important to evaluateadsorption dynamics. In order to determine the mechanismof adsorption processes such as chemical reactionsand removal, the pseudo-first-order adsorptionand the pseudo-second-order were used to examine theexperimental data (Ho, 2004; Ho \& Chiang, 2001; Ho \& McKay, 2004). Adsorption of RR43 and DO85 on MWSD andPAni/MWSD atdifferent conditions was employed in the pseudofirst-order and pseudo-second-order models, and therate constants of the first-order adsorption $\left(k_{1}\right)$ andthe rate constants of the second-order adsorption $\left(k_{2}\right)$ were estimated, respectively.

\subsubsection{Pseudo first order model}

Lagergren kinetic equation describes the adsorptionof liquid-solid systems based on solid capacity. Inorder to distinguish kinetic equations based on concentrationof the solution and adsorption capacity of thesolid, Lagergren first-order rate equation is termed asa pseudo-first-order reaction. The pseudo-first-orderrate equation of Lagergren can be written as follows:

$$
\log \left(q_{e}-q_{t}\right)=\log q_{e}-\frac{k_{1}}{2.303} x t
$$

Where $q_{e}$ and $q_{t}$ are the amounts $(\mathrm{mg} / \mathrm{g})$ of dye adsorbed at equilibrium and at time ( $\mathrm{t}$ ) respectively.

\subsubsection{Pseudo second order model}

The pseudo-second-order rate expression is basedon the sorption capacity of solids but contrary to theprevious model it describes chemisorption's over thewhole adsorption time. The pseudo-second-order rateequation of McKay can be given in the following form:

$$
\frac{\mathrm{t}}{q_{\mathrm{t}}}=\frac{1}{k_{2} q_{\mathrm{e}}^{2}}+\frac{1}{q_{\mathrm{e}}}
$$

where $k_{2}$ is the equilibrium rate constant of the pseudo-second order $\left(\mathrm{g} \mathrm{mg}^{-1} \mathrm{~min}^{-1}\right)$. Plots of $t / q_{\mathrm{t}}$ versus $t$ should give straight lines where slopes and interceptsare $1 / q_{\mathrm{e}}$ and $1 / k_{2} q_{e}^{2}$, respectively. Values of the rate constant $k_{2}$ and sorption capacity $q_{\mathrm{e}}$ can be calculated from these parameters. The resulting data summarized in Table 1 show that using the pseudosecond order kinetic model, the experimental sorption capacity $q_{\mathrm{e}}(\exp )$ values are very close to the calculated sorption capacity $q_{\mathrm{e}}$ (calc). Kinetic data and correlation coefficients $\left(\mathrm{R}^{2}\right)$ confirm that sorption of RR43 and DO85 on MWSD andPAni/MWSDfollow the pseudo-secondorder kinetics model. The pseudo second order model is based on theassumption that the rate-limiting step is a chemical sorption betweenthe adsorbate and adsorbent. This provides the best correlation of thedata for all the three adsorbents.

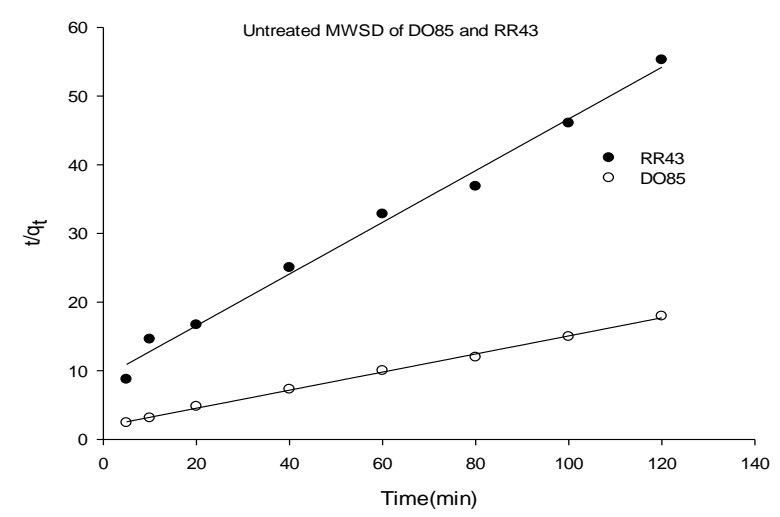


Fig.9.Pseudo second order plot for the adsorption of DO85 and RR43 onto MWSD.

Table 1.Adsorption kinetic parameters of RR43 and DO85onto MWSD and PAni/MWSD

\begin{tabular}{|c|c|c|c|c|c|c|c|}
\hline \multirow{3}{*}{ Dyes } & \multicolumn{6}{|c|}{ Calculation } & \multirow[b]{3}{*}{$\begin{array}{c}\text { Experim } \\
\text { ental }\end{array}$} \\
\hline & \multicolumn{3}{|c|}{ The pseudo-first-order } & \multicolumn{3}{|c|}{ The pseudo-second order } & \\
\hline & $k_{1}\left(\min ^{-1}\right)$ & $\begin{array}{c}q_{\mathrm{e}} \mathrm{cal} \\
(\mathrm{mg} / \mathrm{g})\end{array}$ & $\mathrm{R}^{2}$ & $\begin{array}{c}K_{2} \times 10^{-4} \\
(\mathrm{~g} / \mathrm{mg} \min )\end{array}$ & $\begin{array}{c}q_{\mathrm{e}} \mathrm{cal} \\
(\mathrm{mg} / \mathrm{g})\end{array}$ & $\mathrm{R}^{2}$ & \\
\hline DO85+MWSD & 0.0149 & 1.413 & 0.9968 & 0.00912 & 7.593 & 0.9990 & 6.6857 \\
\hline DO85+TMWSD & 0.0375 & 0.692 & 0.9864 & 0.00643 & 31.153 & 0.9997 & 29.611 \\
\hline RR43+ MWSD & 0.0124 & 3.75 & 0.9966 & 0.0157 & 2.656 & 0.9954 & 2.1714 \\
\hline RR43+TMWSD & 0.0174 & 0.888 & 0.9566 & 0.00251 & 13.755 & 0.9977 & 11.028 \\
\hline
\end{tabular}

\subsubsection{Elovich model}

One of the most useful models for the studies of activated chemisorption is the Elovich equation. It is generally expressed as (Chien and Clayton,1980)

$$
\mathrm{d} q_{t} / \mathrm{dt}=\mathrm{a}_{\exp }\left(-\beta q_{t}\right)
$$

where $q_{t}$ is the amount of solute adsorbed at time $t$, a is the initial adsorption rate $\left(\mathrm{mg} \mathrm{g}^{-1} \mathrm{~min}^{-1}\right)$ and $\beta$ is the desorption constant $\left(\mathrm{g} \mathrm{mg}^{-1}\right)$ during any one experiment. The Elovich equation can be simplified by assuming a $\beta \mathrm{t} \gg \mathrm{t}$ and applying the boundary conditions $q_{t}=0$ at $\mathrm{t}=0$ and $q_{t}=q_{t}$ at $\mathrm{t}=\mathrm{tEq}$. (5) becomes:

The Elovich constants a and $\beta$ can be obtained from the plot of $q_{t}$ vs. $\ln (t)$.

$$
q_{t}=1 / \beta \ln (\mathrm{a} \beta)+1 / \beta \ln (t)
$$

\subsubsection{The intraparticle diffusion model}

The intraparticle diffusion model (Weber et al.,1963) is characterized by a linear relationship between the amounts adsorbed $\left(\mathrm{q}_{\mathrm{t}}\right)$ and the square root of the time and is expressed as

$$
q_{t}=\left(\mathrm{K}_{\mathrm{id}}\right) \mathrm{t}^{0.5}
$$

where $q_{t}(\mathrm{mg} / \mathrm{g})$ is the amount of metal ions adsorbed at time $t(\mathrm{~min})$ and $\mathrm{K}_{\mathrm{id}}$ is the initial rate of the intraparticle diffusion $\left(\mathrm{mg}\left(\mathrm{g} \mathrm{min}^{0.5}\right)^{-1}\right)$. The rate constant of intraparticle diffusion $\mathrm{K}_{\mathrm{id}}$ was determined by plotting $q_{t}$ as a function of the square root of the time.

The pseudo first order model and Elovich model did not applythroughout all the contact times For all the two adsorbents. Thecalculated $q_{e}$ values are lower than the experimental value.

The graph of $q_{t}$ vs. $\mathrm{t}^{0.5}$ shows a non-linear distribution of points, withtwo distinct portions (Figure not shown). The first, sharp portion is theexternal surface adsorption or instantaneous adsorption stage. The secondlinear portion indicates the existence of intraparticle diffusion in theprocess. Since the first portion is completed within $10 \mathrm{~min}$, it canbeneglected and then the stage of intraparticle diffusion control is attainedand continues from $10 \mathrm{~min}$ to $1 \mathrm{~h}$. The anionic dyes are slowly transportedthrough the pores of the particle and is finally retained in the micropores.In general, the slope of the line in 2 portions is called as intraparticlediffusion rate constant. The rate constants of intraparticle diffusion $\left(\mathrm{K}_{\mathrm{id}}\right)$ alongwith their regression coefficient are shown in Table 2 . $\mathrm{TheK}_{\mathrm{id}}$ valuesled to the conclusion that intraparticle diffusion is the rate determiningstep in the adsorption of RR43 and DO85on MWSD and PAni/MWSD.(Helen and Lima Rose,2010).

Table (2) EstimatedElovichmodelandIntraparticlediffusionmodel kinetic parameters for DO85,RR43 dye adsorption by (MWSD) and (PAni/MWSD).

\begin{tabular}{|c|c|c|c|c|c|}
\hline \multirow{2}{*}{ Dyes } & \multicolumn{2}{|l|}{ Elovich model } & \multicolumn{2}{c|}{ Intraparticle diffusion model } \\
\cline { 2 - 6 } & $\beta\left(\mathrm{g} \mathrm{mg}^{-1}\right)$ & $\begin{array}{c}\alpha\left(\mathrm{mg} \mathrm{g}^{-1}\right. \\
\left.\mathrm{min}^{-1}\right)\end{array}$ & $\mathrm{R}^{2}$ & $\begin{array}{c}\mathrm{K}_{\mathrm{id}}\left(\mathrm{mg} \mathrm{g}^{-1}\right. \\
\left.\mathrm{min}^{-0.5}\right)\end{array}$ & $\mathrm{R}^{2}$ \\
\hline DO85+MWSD & 0.5259 & 0.6239 & 0.9989 & 0.5327 & 0.9630 \\
\hline D085+TMWSD & 6.8106 & 0.1772 & 0.9929 & 1.5248 & 0.9101 \\
\hline RR43+ MWSD & 0.4020 & 1.8604 & 0.9852 & 0.2005 & 0.9760 \\
\hline RR43+ TMWSD & 2.5340 & $\mathbf{0 . 3 6 1 2}$ & 0.9889 & 1.0422 & 0.9876 \\
\hline
\end{tabular}

\subsection{Adsorption isotherms}


The isotherm experiments were carried out for known concentration at $\mathrm{pH}$ value6.0 for a concentration range of 5-100ppm. All solutions have a fixed specific mass of MWSD (0.7gm). The experimental data were fitted to various models such as Langmuir, Freundlichand Temkin.

\subsubsection{Langmuir isotherm model}

$$
\frac{1}{X}=\frac{1}{X_{m}}+\frac{1}{b X_{m} C_{e}}
$$

where, $\mathrm{C}_{\mathrm{e}}$ is the equilibrium concentration of the dye solution $\left(\mathrm{mg} \mathrm{L}^{-1}\right), \mathrm{X}$ is the amount of dye sorbed by the adsorbent $\left(\mathrm{mg} \mathrm{g}^{-1}\right), \mathrm{X}_{\mathrm{m}}$ is the maximum amount of dye sorbed, $\mathrm{b} /\left(\mathrm{L} \mathrm{mg}^{-1}\right)$ is a Langmuir constant for the energy of sorption. Values of $b$ and $X_{m}$ were calculated from the slope and intercept of the linear plot. The Langmuir model deals with monolayer adsorption and constant adsorption energy.

From Table (3) the sorption capacity, $X_{m}$, which is a measure of the maximum sorption capacity corresponding to complete monolayer coverage, showed that the adsorbent had a mass capacity and the adsorption coefficient, b Langmuir constant for the energy of sorption for DO85 greaterthan RR43. This observation was probably due to its have more active site.

Furthermore the essential characteristics of a Langmuir isotherm can be expressed in terms of a dimensionless separation, the type of isotherm and is defined by the following equation:

$$
R_{L}=\frac{1}{1+b C_{0}}(9)
$$

Where b Langmuir isotherm constant; $\mathrm{C}_{\mathrm{o}}$ initial dye concentration. The value of $R_{\mathrm{L}}$ indicates the shape of the isotherms to be either unfavorable $\left(R_{\mathrm{L}}>1\right)$, linear $\left(R_{\mathrm{L}}=1\right)$, favorable $\left(0<R_{\mathrm{L}}<1\right)$ or irreversible $\left(R_{\mathrm{L}}=0\right)$. The separation parameters for the two dyes are less than unity indicating that MWSD adsorbent is an excellent adsorbent for the two dyes.
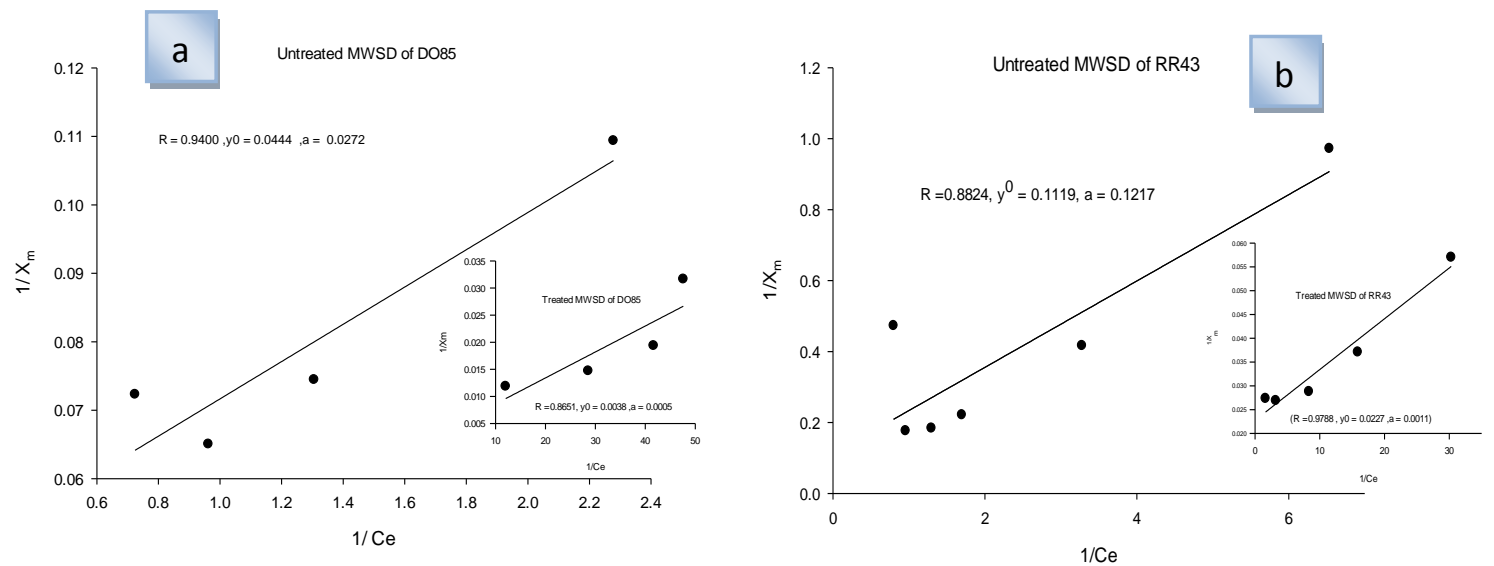

Fig. 10.Langmuir isotherm obtained for sorption of DO85 (a)and RR43 (b)by MWSD and treated MWSD

Table 3.Isotherm constants for the adsorption of RR43 and DO85onto MWSD and PAni/MWSD.

\begin{tabular}{||c|c|c|c|c|c|c|c|c|c|c|c||}
\hline \multirow{2}{*}{ Dyes } & \multicolumn{4}{|c|}{ Langmuir } & \multicolumn{4}{c|}{ Freundlich } & \multicolumn{3}{|c||}{ Temkin } \\
\cline { 2 - 13 } & $\mathbf{b}$ & $\mathbf{1} / \mathbf{X}_{\mathbf{m}}$ & $\mathbf{X}_{\mathbf{m}}$ & $\boldsymbol{R}_{\mathbf{L}}$ & $\mathbf{R}^{2}$ & $\mathbf{n}$ & $\mathbf{K}_{\mathbf{f}}$ & $\mathbf{R}^{2}$ & $\mathbf{b}_{\mathbf{T}}$ & $\mathbf{K}_{\mathbf{T}}$ & $\mathbf{R}^{2}$ \\
\hline DO85+ MWSD & 0.0011 & 0.0444 & 22.52 & 0.7102 & 0.940 & 1.1495 & 0.9552 & 0.9268 & 0.0001 & 0.0014 & 0.8603 \\
\hline DO85+ TMWSD & 0.1217 & 0.0038 & 263.16 & 0.9925 & 0.865 & 4.8616 & 0.0211 & 0.9593 & 0.0001 & 0.0144 & 0.9424 \\
\hline RR43+ MWSD & 0.0005 & 0.1119 & 8.9366 & 0.3539 & 0.882 & 1.0117 & 0.9211 & 0.9823 & 0.0007 & 0.0018 & 0.9824 \\
\hline RR43+ TMWSD & 0.0272 & 0.0227 & 44.053 & 0.9852 & 0.978 & 1.6723 & 0.2339 & 0.8660 & 0.0009 & 0.0106 & 0.9128 \\
\hline
\end{tabular}

\subsubsection{Freundlich isotherm}

The Freundlich model was chosen to estimate the adsorption intensity of the sorbate on the sorbent surface. The Freudlich model is represented in equation 


$$
\log \frac{X}{m}=\log K_{f}+\frac{1}{n} \log C_{e}
$$

where $\mathrm{X} / \mathrm{m}$ is the equilibrium adsorption capacity $\left(\mathrm{mg} \mathrm{g}^{-1}\right), \mathrm{C}_{\mathrm{e}}$ is the equilibrium or residual concentration $\left(\mathrm{mg} \mathrm{L}^{-1}\right)$ of dye in the solution, and $\mathrm{K}$ and $1 / \mathrm{n}$ are empirical Freundlich constants indicating sorption capacity of the adsorbent and intensity of the adsorption $\left(\mathrm{mg} \mathrm{g}^{-1}\right)$, respectively. In the Freundlich adsorption system, values of $\mathrm{n}$ and $\mathrm{K}$ were calculated from the slope and intercept of the linear plot of $\log$ $\mathrm{X} / \mathrm{m}$ against $\log \mathrm{C}_{\mathrm{e}}$.

The experimental data from the batch sorption study of the anionic dyes such as RR43 and DO85by MWSD were illustrated in Table (3) and plotted logarithmically using the linear Freundlich isotherm equation. The linear Freundlich isotherm constants for RR43 and DO85 are presented in table (3) . The ultimate adsorption capacity $K_{f}$, of the adsorbent was calculated from the isothermal linear regression equation. The increase of negative charge due to the presence of $-\mathrm{COOH},-\mathrm{SO}_{3} \mathrm{H}$, and $-\mathrm{OH}$ groups on the surface of the adsorbent that enhances the electrostatic force like vanderwaal's between the adsorbent surface and dye ion, which increases the adsorption of DO85. The $K_{f}$ value of DO85 is greater than that of RR43, suggesting and confirming that DO85has greater adsorption tendency towards the maple wood sawdust than the other dye. The values of $n$ were found to be greater than 1 which may be attributed to the distribution of surface sites or any factor responsible for a decrease in dye maple woodsawdust interaction with increasing surface density.

\subsubsection{Temkin isotherm model}

The Temkin adsorption isotherm model was chosen to evaluate the adsorption potentials of the adsorbent for adsorbates. The linear form of the Temkin isotherm model as shown in equation 11 was plotted as $q_{\mathrm{e}}$ against $\ln C_{\mathrm{e}}$.

$$
q_{e}=\frac{R T}{b_{t}} \ln K_{t}+\frac{R T}{b_{t}} \ln C_{e}
$$

where the $1 / b_{T}$ indicates the adsorption potential of the adsorbent and $K_{t}$ is the Temkin isotherm constant $\left(\mathrm{dm}^{3} \mathrm{~g}^{-1}\right)$. The experimental data from the batch sorption study of the three dyes by maple woodsawdustare illustrated in Table (3). A plot of $\mathrm{q}_{\mathrm{e}}$ versus $\ln C_{\mathrm{e}}$ yielded linear lines which enable the determination of the isotherm constants $K_{t}$ and $b_{\mathrm{T}}$ from intercepts and slopes respectively.

\section{Conclusion}

In this study we investigated The removal of two anionic dyes DO85 and RR43 using MWSD and PAni/MWSD. The results showed that the adsorptioncapacity at equilibrium of both dyes was favorable at neutral $\mathrm{pH}$. Theadsorption data fitted well the Langmuir isotherm, witha maximum monolayer adsorption capacity $63.16 \mathrm{mg} \mathrm{g}^{-1}$ and $44.053 \mathrm{mg} \mathrm{g}^{-1}$ for the DO85 and RR43, respectively. The adsorptionkinetics was best described by the pseudo-second-order kinetic model. In addition, the kinetic data of the adsorption process had a good agreement with the pseudo-second order model. From the results of the

present study, it is concluded that PAni/MWSD was found to be suitable adsorbent for the removal of both (DO85) and reactive (RR43) dyes (anionic dyes).

\section{Reference}

Chen, D., Lei, S., Chen, Y., 2011a. A single polyanilineanofiber field effect transistor and its gas sensing mechanisms. Sensors 11, 6509e6516.

Chien, S.H. Clayton,W.R. (1980) Soil Sci. Soc. Am. J. 44 265-268.

Crini, G., 2006. Non-conventional low-cost adsorbents for dye removal: a review. Bioresour.Technol. 97, 1061e1085.

G_oes, M.M., Keller, M., Oliveira, V.M., Villalobos, L.D.G., Moraes, J.C.G.,Carvalho, G.M., 2016. Polyurethane foams synthesized from cellulose-basedwastes: kinetics studies of dye adsorption. Ind. Crops Prod.85, 149e158.

Garg VK, Gupta R, Kumar R, Gupta RK., 2004. Adsorption of chromium from aqueous solution on treated sawdust. Bioresour Technol;92:79.

Ho, Y. S., \& Chiang, C. C. (2001). Sorption studies ofacid dye by mixed sorbents. Adsorption, 7, 139-147. DOI:10.1023/A:1011652224816. 
Ho, Y.-S. (2004). Citation review of Lagergren kinetic rate equation on adsorption reactions.Scientometrics, 59, 171-177.

Jaymand, M., 2013.Recent progress in chemical modification of polyaniline.Prog.Polym. Sci. 38, $1287 \mathrm{e} 1306$.

Kalavathy, M. H. Lima Rose Miranda (2010). Comparison of copper adsorption from aqueous solution using modified and unmodified Heveabrasiliensis saw dust. Desalination 255 165-174

Kamran Zarrini, Abd Allah Rahimi, FarzanehAlihosseini*, HosseinFashandi., 2017. Highly efficient dye adsorbent based on polyaniline-coated nylon-6Nanofibers.

Lebo, S. E., Jr., Gargulak, J. D., \& McNally, T. J. (2001)Lignin. In J. I. Kroschwitz, \& M. HoweGrant (Eds.), Kirk-Othmer encyclopedia of chemical technology (5th ed.Vol. 15, pp. 1-24). New York, NY, USA: Wiley. DOI:10.1002/0471238961.1209071412, 0914.a01.pub2.

Lee, L.Y., Gan, S., Yin Tan, M.S., Lim, S.S., Lee, X.J., Lam, Y.F., 2016. Effective removal of Acid Blue 113 dye using overripe Cucumissativus peel as an eco-friendly biosorbent from agricultural residue. J. Clean. Prod. 113, 194e203.

Maas, R., Chaudhari, S., 2005.Adsorption and biological decolourization of azodyeReactive Red 2 in semicontinuous anaerobic reactors.Process Biochem. 40,699e705.

Onyango, M.S. Y. Kojima, O. Aoyi, E.C. Bernardo, H. Matsuda, J . Colloid Interface Sci. 279, (2004) 341-350.

P.C.C. Faria, J.J.M. Orfao, M.F.R. Pereira, Water Res. 38 (2004) 2043-2052.

Rafatullah, M., Sulaiman, O., Hashim, R., Ahmad, A., 2010. Adsorption of methylene blue on lowcost adsorbents: a review. J. Hazard. Mater.177, 70e80.

Reza Ansari , Zahra Mosayebzadeh.2011. Application of polyaniline as an efficient and novel adsorbent for azo dyes removal from textile wastewaters Chemical Papers 65 (1) 1-8 (11)DOI: 10.2478/s11696-010-0083-x

Robinson, T., McMullan, G., Marchant, R., Nigam, P., 2001. Remediation of dyes in textile effluent: a critical review on current treatment technologies with aproposed alternative. Bioresour.Technol. 77, $247 \mathrm{e} 255$.

Shukla A, Zhang YH, Dubey P, Margrave JL, Shukla SS., 2002. The role of sawdust in the removal of unwanted materials from water. J Hazard Mater;95:137.

Srivastava, V.C. I.D. Mall, I.M. Mishra,2008.Chem. Eng. Process. 47 1269-1280.

Syed, A.A., Dinesan, M.K., 1991. Review: polyanilineda novel polymeric material.Talanta

38, $815 \mathrm{e} 837$.

Venkat S. Mane, P.V. Vijay Babu.,2013. Kinetic and equilibrium studies on the removal of Congo red from aqueous solution using Eucalyptus wood (Eucalyptus globulus) saw dustJournal of the Taiwan Institute of Chemical Engineers 44 81-88.

Weber, W.J., Morris, J.C. Sanit. J. Eng. Div. (1963) Am. Soc. Civ. Eng. 89 31-60.
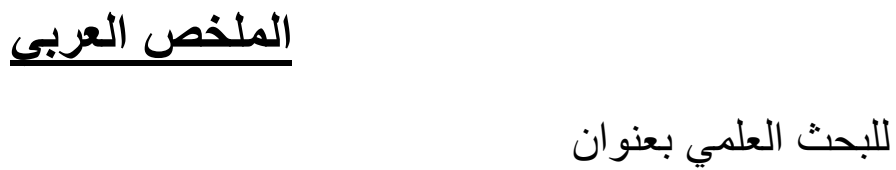

\section{Application of modified Maple Wood Saw Dust with polyaniline for the removal of Anionic Dyes From waste water : Kinetics and Isotherm Studies}


(في هذا العمل، يتم تطبيق تغطية البولي انيلين على نثارة الخشب وذللك لإز الة الأصباغ الأيونية

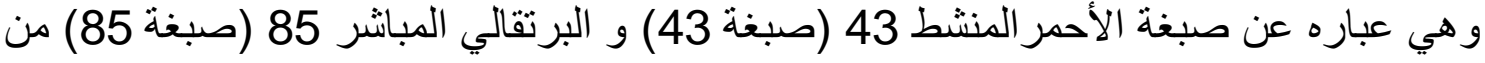

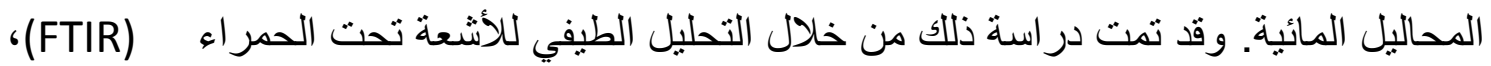

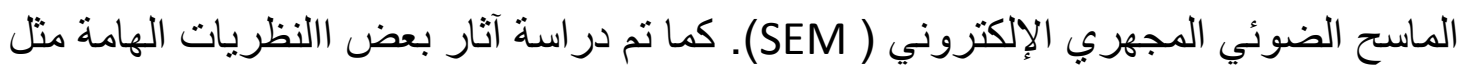

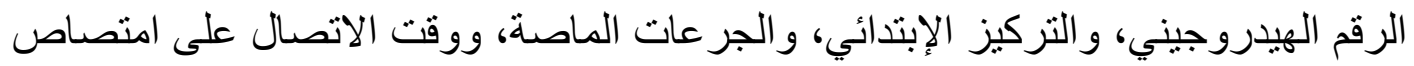

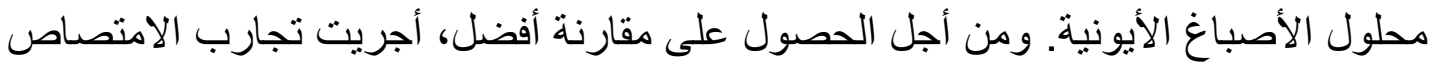

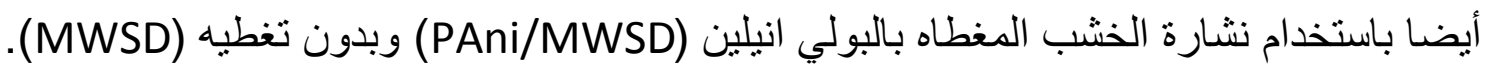

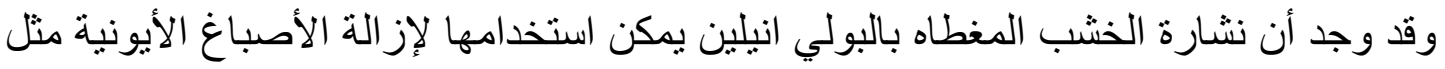

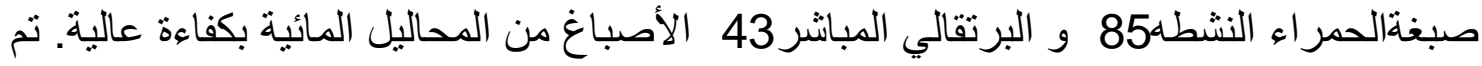

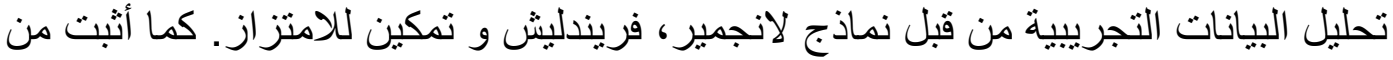

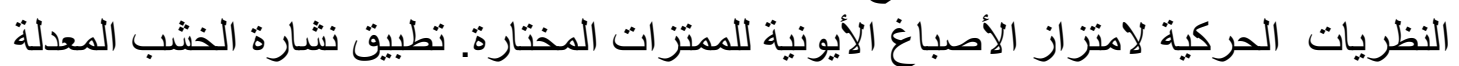

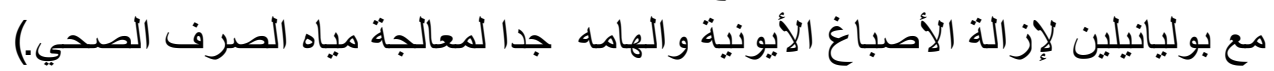

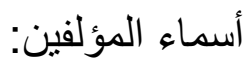
1-أ.م.د/عبير أحمد إمام استاذ مساعد الكيمياء الفيزيائية -جامعة الأزهر 2- أ.م.د/نورا هلال استاذ مساعد الكيمياء الفيزيائية -جامعة الأزهر 3- أ.د/أمينه حمادة استاذ الكيمياء الفيزيائية -جامعة الأزهر 4- أ.د/نجوي بدوي استاذ الكيمياء الفيزيائية -جامعة الأزهر 5- الطالبه /يمني عبد المنعم محمد-جامعة الأزهر 